\title{
EFFICACY AND SAFETY OF VACCINATION AGAINST HEPATITIS B VIRUS WITHOUT PRIOR SCREENING TEST
}

\author{
AKHTER R ${ }^{1}$, HOSSAIN MZ², RABBANI SB ${ }^{3}$, HOSSAIN SF $^{4}$, CHAKRABORTY A $^{5}$, BISWAS PK ${ }^{6}$
}

\begin{abstract}
:
Hepatitis $B$ virus infection is a major global health problem. There is no specific treatment for acute hepatitis $B$ infection. A safe and effective vaccine, which has been available for more than 30 years, is $95 \%$ effective in preventing the development of chronic infection. The employee of Bangladesh Bank and their family member had received 4 doses of Engirex $B$ according to schedule 0, 1,6,12 months without any prior screening test. They received 4 th booster dose in 2009.The goal of this study to find out and compare the efficacy and safety of vaccination against HBV without prior screening test. The employee (more than 50years old) underwent annul health check up and their serum HBsAg and Anti-HBs (quantative) were measured in the Immunology department of Bangladesh Institute of Research \& Rehabilitation in Diabetes, Endocrine and Metabolic Disorders (BIRDEM) and Popular diagnostic center. HBsAg is measured by MEIA method. Anti-HBs (quantative) are measured by chemiluminescence EIA method. 491 subjects have been studied. Among them 480(97.76\%) are HBsAg negative and 11(2.24\%) cases are HBsAg positive. Ten out of eleven HBsAg positive cases are male. The average antiHBs titer of the employee is $610.9958(0->2000 \mathrm{~m} \mathrm{IU} / \mathrm{ml})$. The average anti-HBs titer of female $(n=90)$ employee is $713(10->2000 \mathrm{mIU} / \mathrm{ml})$ and average anti-HBs titer of male $(n=390)$ employee is $587.77(0->2000 \mathrm{~m} \mathrm{IU} / \mathrm{ml})$. Female employee developed higher immunity $(73.33 \%)$ than male employee (56.41\%). So it is presumptive that vaccine is safe and effective and we can continue vaccination without prior screening test.
\end{abstract}

Key word: HBsAg, Anti-HBs, HBV vaccine.

J Dhaka Med Coll. 2016; 25(1): 16-25

\section{Introduction:}

Hepatitis B virus infection is a major global health problem .Worldwide it is the 10th leading cause of death. In Western countries, the disease is relatively rare and acquired primarily in adulthood, whereas in Asia and most of Africa, chronic HBV infection is common and usually acquired perinatally or in childhood. Prevalence of Hepatitis B in Bangladesh is yet to be ascertained by a reliable study. Data available from different studies show that it is ranges between 0.8 and $5.4 \% 1$, $2,3,4,5$ based on the detection of HBsAg antigen. Relying on these statistics Bangladesh can be categorized as an intermediate endemic zone for HBV ${ }^{6}, 7$.Globally, variation in prevalence depends on age, sex, country, income, education, life style and co-morbidity. Lifetime risk of infection is $20 \%-60 \%$ and infections occur in all age groups. ${ }^{8}$ The estimated lifetime risk of HBV infection in the United States varies from almost $100 \%$ for the highest-risk groups to less than $5 \%$ for the population as a whole. ${ }^{9}$

The virus is transmitted through contact with the blood or other body fluids of an infected person. The most important routes of transmission are perinatal and sexual contact, either heterosexual or homosexual, with an infected person. In the past two decades, outbreaks of hepatitis B have occurred in longterm care facilities (e.g., assisted living facilities and nursing homes) as the result of lack of infection control practices related to blood glucose monitoring. Hepatitis B virus remains infectious for at least 7 days on environmental surfaces and is transmissible in the absence of visible blood. Direct percutaneous inoculation of HBV by needles during injection-drug use is an important mode

1. Dr. Rabeya Akther, Deputy Chief Medical Officer, Bangladesh Bank Medical Center, Dhaka, Bangladesh

2. Dr. Mohammad Zaid Hossain, Associate Professor, Dept. of Medicine, Dhaka Medical College \& Hospital, Dhaka.

3. Dr. Safia Binte Rabbani, Medicine Specialist, United Hospital Ltd.

4. Dr. Syeda Fahmida Hossain, Junior Consultant Medicine, United Hospital Ltd.

5. Dr. Ashim Chakraborty, Resident Physician, Medicine, Sir Salimullah Medical \& Mitford Hospital, Dhaka

6. Dr. Prodip Kumar Biswas, Associate Professor, Dept. of Medicine, Dhaka Medical College, Dhaka

Correspondence : Dr. Rabeya Akther, Deputy Chief Medical Officer, Bangladesh Bank Medical Center, Motijheel, Dhaka, Mobile: 01817517100, E-mail: rabeya.akter@bb.org.bd

Received: 01 January 2016

Accepted: 20 March 2016 
of transmission. Breaks in the skin without overt needle puncture, such as fresh cutaneous scratches, abrasions, burns, or other lesions, may also serve as routes for entry. Nosocomial exposures such as transfusion of blood or blood products, hemodialysis, use of meters and lancets for glucose monitoring, insulin pens, and needle-stick or other "sharps" injuries sustained by hospital personnel have all resulted in HBV transmission. ${ }^{8}$

An estimated 240 million people are chronically infected with hepatitis B (defined as hepatitis B surface antigen positive for at least 6 months). An estimated 2 billion persons worldwide have been infected with HBV, and more than 350 million persons have chronic, lifelong infections. HBV infection is an established cause of acute and chronic hepatitis and cirrhosis. It is the cause of up to $50 \%$ of hepatocellular carcinomas (HCC). The World Health Organization estimated that more than 600,000 persons died worldwide in 2002 of hepatitis B-associated acute and chronic liver disease. ${ }^{8}$ Hepatitis $B$ is an important occupational hazard for health workers. The role of the HBV carrier is basic to the epidemiology of HBV transmission. A carrier is defined as a person who is HBsAg positive on at least 2 occasions, at least 6 months apart. Although the degree of infectivity is best correlated with HBeAg positivity, any person with a positive test for HBsAg is potentially infectious. The likelihood of developing the carrier state varies inversely with the age at which infection occurs. During the perinatal period, HBV transmitted from $\mathrm{HBeAg}$-positive mothers results in HBV carriage in up to $90 \%$ of infected infants, whereas $6 \%-10 \%$ of acutely infected adults become carriers ${ }^{7}$. HBV is about 100 times more infectious than HIV. ${ }^{10}$

HBsAg is the most commonly used test for diagnosing acute HBV infections or detecting carriers. HBsAg can be detected as early as 1 or 2 weeks and as late as 11 or 12 weeks after exposure to HBV when sensitive assays are used. The presence of HBsAg indicates that a person is infectious, regardless of whether the infection is acute or chronic.
There is no specific treatment for acute hepatitis B infection. Treatment is supportive. However, those who develop antibody to HBsAg (anti-HBs) during convalescence after acute HBV infection or following hepatitis B vaccination, are usually protected against subsequent infection. Hepatitis B viral infection is a preventable disease. A safe and effective vaccine, which has been available for more than 30 years, is $95 \%$ effective in preventing the development of chronic infection. A titer of at least $1 \mathrm{mIU} / \mathrm{ml}$ or more was interpreted as seroconversion and a titer above $10 \mathrm{mIU} / \mathrm{ml}$ was considered as seroprotection. ${ }^{11}$ The vaccine produces neither therapeutic nor adverse effects in HBV carrier ${ }^{12}$. When primary vaccination produces anti-HBs (Hepatitis B surface antibody) level $>100 \mathrm{~m} \mathrm{IU} / \mathrm{ml}$, it is considered to be adequate response or the vaccine is called responders. If between 10-100 m IU/ml, then hypo responders and if it is $<10 \mathrm{~m} \mathrm{IU} / \mathrm{ml}$, then there is no response or non responder.

In 1991, the World Health Organization (WHO) recommended that all countries introduce a policy of universal hepatitis $B$ vaccination to prevent and control HBV infection and its long term sequelae on a global scale.. Hepatitis B vaccine for infants had been introduced nationwide in 184 countries by the end of 2014 . Global coverage with 3 doses of hepatitis B vaccine is estimated at $82 \%$ and is as high as $92 \%$ in the Western Pacific ${ }^{13}$

Bangladesh (since late 2004) has started incorporating the $\mathrm{HBV}$ vaccination into national immunization program with the schedule of immunizing babies at 6,10 and 14 weeks of birth.

In the mid 1980s, recombinant DNA hepatitis $B$ vaccines containing HBsAg expressed in HBV transfected yeasts (i.e. Saccharomyces cerevisiae), the so-called "second" generation hepatitis B vaccine, were commercialized. This new technology offered the potential of unlimited production, which allowed the hepatitis $B$ vaccine to become one of the most widely used in the world. Several hundred million doses of hepatitis $B$ vaccine have been administered worldwide with an excellent record of safety and efficacy. ${ }^{14}$ 
Bangladesh Bank is an autonomous body situated in Dhaka, Bangladesh. A mixture of highly educated and educated people is working in this institute. They enjoy some medical facility. Considering the seriousness of HBV infection, the employee and their family member were vaccinated against HBV in 20002001 and they had received 4 doses Engirex B according to schedule $0,1,6,12$ months without any prior screening test. They received 4 th booster dose in 2009. The goal of this study to find out and compare the efficacy and safety of vaccination against $\mathrm{HBV}$ without prior screening test.

Methodology: This is a large, prospective, longitudinal, descriptive and opportunistic type study carried out in Bangladesh Bank Medical Center, Motijheel, and Dhaka. The employee (more than 50years old) underwent annul health check up in 2013-2014 and their serum HBsAg and Anti-HBs (quantative) were measured in the Immunology department of Bangladesh Institute of Research \& Rehabilitation in Diabetes, Endocrine and Metabolic Disorders (BIRDEM) and Popular diagnostic center. HBsAg is measured by MEIA method. Anti-HBs (quantative) is measured by chemiluminescence EIA method. Data were collected from employee's digital medical records. All data were checked for completeness and consistencies. Then data were complied and appropriate statistical analysis was done using computer based Microsoft Excel windos7 professional.

\section{Observation and results:}

For the purpose of the study, 491 subjects have been studied. Table-I showed age sex and HBsAg status of the employee. Out of $491 \mathrm{employee}$ $91(18.53 \%)$ are female and $400(81.47 \%)$ are male employee. Median age of the employee is 55.78(51-59) years. Average age of female employee is 56(50-59) years and of male employee is 55.64(50-59) years. Among them $480(97.76 \%)$ are HBsAg negative and $11(2.24 \%)$ cases are HBsAg positive. Ten out of eleven HBsAg positive cases are male.

Table-II showed antibody titer (anti-HB) 4 to 5 years after vaccination. The average antibody titer of the employee is $610.9958(0->2000 \mathrm{~m}$
$\mathrm{IU} / \mathrm{ml})$. The average antibody titer of the healthy employee is $875.5(0->2000 \mathrm{~m} \mathrm{IU} / \mathrm{ml})$. The average antibody titer of the diseased employee is $618.58(0->2000 \mathrm{~m} \mathrm{IU} / \mathrm{ml})$. The average antibody titer of female $(n=90)$ employee is $713(10->2000 \mathrm{mIU} / \mathrm{ml})$. The average antibody titer of healthy female $(n=15)$ is $977.69(103->2000 \mathrm{~m} \mathrm{IU} / \mathrm{ml})$. The average antibody titer of diseased female $(n=75)$ is $652.82(0->2000 \mathrm{~m} \mathrm{IU} / \mathrm{ml})$. The average antibody titer of male $(\mathrm{n}=390)$ employee is $587.77(0->2000 \mathrm{~m} \mathrm{IU} / \mathrm{ml})$. The average antibody titer of healthy male $(\mathrm{n}=121)$ is $594.39(0->2000 \mathrm{~m} \mathrm{IU} / \mathrm{ml})$. The average antibody titer of diseased male $(\mathrm{n}=269)$ is $585(0-$ $>2000 \mathrm{~m} \mathrm{IU} / \mathrm{ml}$ ). Seroconversion (antibody titer $>1 \mathrm{~m} \mathrm{IU} / \mathrm{ml}$ ) occur among 432(87.98\%) and Seroprotection (antibody titer $>10 \mathrm{~m} \mathrm{IU} / \mathrm{ml}$ ) seen among 380(77.39\%). Female employee developed higher immunity (73.33\%) than male employee $(56.41 \%)$. Among the positive cases, $6(1.23 \%)$ are diseased and all are male .They continued treatment and remaining 5(1.02\%) are carrier. They continue follow up procedure and needs no treatment.

Table-III showed distribution of total HBsAg negative employee $(n=480)$ according to level of immunity. 286(59.58\%) employee have good protection against HBV. Among them 220 $(56.4 \%)$ are male and $66(73.33 \%)$ are female. $94(19.58 \%)$ employee have low protection. Among them $80(20.51 \%)$ are male and $14(15.55 \%)$ are female. $100(20.83 \%)$ employee have no protection against HBV. Among them $90(23.07 \%)$ are male and $10(11.11 \%)$ are female.

Table-IV, figure 1 and 2 showed that $136(28.33 \%)$ employee are disease free and $344(71.67 \%)$ employee are suffering from different diseases. It also showed distribution of total HBsAg negative diseased employee and comparison between male and female employee. Data showed that female employee is more diseased than male employee. Total $136(28.33 \%)$ employee are diseases free. Among them $121(24.59 \%)$ are male and $15(2.87 \%)$ are female employee. $38(9.22 \%)$ male are disease free and they have no immunity.

$272(56.67 \%)$ employee are suffering from hypertension. Among them 210(53.85\%) are 
male and 62(68.89\%) are female employee. $179(37.29 \%)$ employee are suffering from diabetes. Among them 134(34.36\%) are male and $45(50 \%)$ are female employee. 81 (16.88\%) employee suffering from heart disease. Among them 69(17.69\%) are male and 12(13.33\%) are female. 59(12.29\%) employee are suffering from bronchial asthma. Among them 40(10.26\%) are male and $19(21.11 \%)$ are female. $26(5.41 \%)$ employee suffering from chronic kidney disease .Among them $19(4.87 \%)$ are male and $7(7.78 \%)$ are female. $16(3.33 \%)$ employee suffering from hypothyroidism. Among them 9(2.3\%) are male and $7(7.78 \%)$ are female. Table-V showed comparison between employee those who fail to develop immunity $(n=100)$ and seroprotective group $(\mathrm{n}=380)$. Regarding disease prevalence, there is no significant difference. $100(20.83 \%)$ employee are failing to develop immunity. Among them 38 male employee are disease free. $62 \%$ employee is suffering from different diseases. Among them 52\% are male, 10\% are female. Among the seroprotective group, $300(75 \%)$ are male employee and 80 (88.88\%) are female employee. Seroprotection found more among female than male.

Table-I

Age, sex and HBsAg status of the employee ( $n=491)$

\begin{tabular}{lccccc}
\hline Sex & Total no & Age (years) & HBsAg -ve & HBsAg +ve & Percentage \\
\hline Female & 91 & $56(51-59)$ & 90 & 1 & $18.53 \%$ \\
Male & 400 & $55.64(50-59)$ & 390 & 10 & $81.47 \%$ \\
Total & 491 & $55.78(50-59)$ & $480(97.76 \%)$ & $11(2.24 \%)$ & \\
\hline
\end{tabular}

Table-II

Anti-HBs titer 4-5 years after 4th booster dose

\begin{tabular}{llll}
\hline Sex & Healthy/ Diseased & Number of employee & Antibody titer \\
\hline Female & Healthy & 15 & $977.69(103-2000) \mathrm{mIU} / \mathrm{ml}$ \\
& Diseased & 75 & $652.82(0-2000) \mathrm{mIU} / \mathrm{ml}$ \\
& Total / Average & 90 & $713(0-2000) \mathrm{mIU} / \mathrm{ml}$ \\
& Seroprotection & 80 & $88.88 \%$ \\
Male & Healthy & 83 & $774(10-2000) \mathrm{mIU} / \mathrm{ml}$ \\
& Healthy but no immunity & 38 & $(0-9) \mathrm{mIU} / \mathrm{ml}$ \\
& Diseased & 269 & $585(0-2000) \mathrm{mIU} / \mathrm{ml}$ \\
Average antibody titer & 400 & $587.77 \mathrm{mIU} / \mathrm{ml}$ \\
Average antibody titer for healthy employee & $75 \%$ \\
Average antibody titer for diseased employee & $610.9958(0-2000) \mathrm{mIU} / \mathrm{ml}$ \\
Seroconvertion ( antibody titer $>1 \mathrm{mIU} / \mathrm{ml})$ & $875.5 \mathrm{mIU} / \mathrm{ml}$ \\
Seroprotection ( antibody titer $>10 \mathrm{mIU} / \mathrm{ml})$ & $618.5 \mathrm{mIU} / \mathrm{ml}$ \\
\hline
\end{tabular}

Table-III

Distribution of total HBsAg negative employee $(n=480)$ according to immunity

\begin{tabular}{lccc}
\hline & Male $(\mathrm{n}=400)$ & Female $(\mathrm{n}=91)$ & Total $(\mathrm{n}=491)$ \\
\hline HBsAg Positive & $10(2.5 \%)$ & $1(1.1 \%)$ & $11(2.24 \%)$ \\
HBsAg Negative & $390(97.5 \%)$ & $90(98.9 \%)$ & $480(97.76 \%)$ \\
Good immunity & $220(56.4 \%)$ & $66(73.33 \%)$ & $286(59.58 \%)$ \\
Low immunity & $80(20.51 \%)$ & $14(15.55 \%)$ & $94(19.58 \%)$ \\
No immunity & $90(23.07 \%)$ & $10(11.11 \%)$ & $100(20.83 \%)$ \\
\hline
\end{tabular}


Table-IV

Distribution of total HBsAg negative Diseased employee ( $n=480$ )

\begin{tabular}{lccc}
\hline & Male $(\mathrm{n}=390)$ & Female $(\mathrm{n}=90)$ & Total(n=480) \\
\hline Disease free & $121(31 \%)$ & $15(16.67 \%)$ & $136(28.33 \%)$ \\
No immunity, no disease & $38(9.74 \%)$ & 0 & $38(7.9 \%)$ \\
Diseased & $269(68.97 \%)$ & $75(83.33 \%)$ & $344(71.67 \%)$ \\
HTN & $211(54 \%)$ & $64(71 \%)$ & $275(57.29 \%)$ \\
DM & $132(33.84 \%)$ & $45(50 \%)$ & $177(36.87 \%)$ \\
IHD & $69(17.69 \%)$ & $12(13.33 \%)$ & $81(16.88 \%)$ \\
BA & $40(10.26 \%)$ & $19(21.11 \%)$ & $59(12.29 \%)$ \\
CKD & $19(4.87 \%)$ & $7(7.78 \%)$ & $26(5.41 \%)$ \\
Hypothyroidism & $9(2.3 \%)$ & $7(7.78 \%)$ & $16(3.33 \%)$ \\
\hline
\end{tabular}

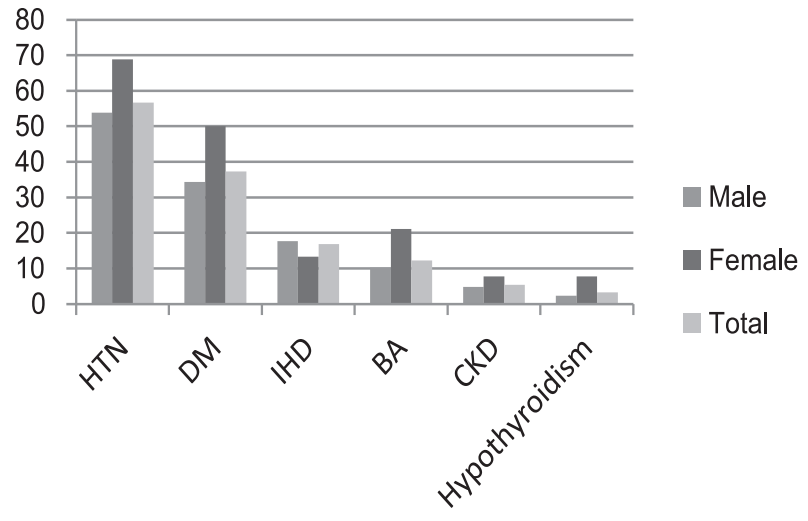

Fig.-1: Distribution of total HBsAg negative Diseased employee $(n=480)$

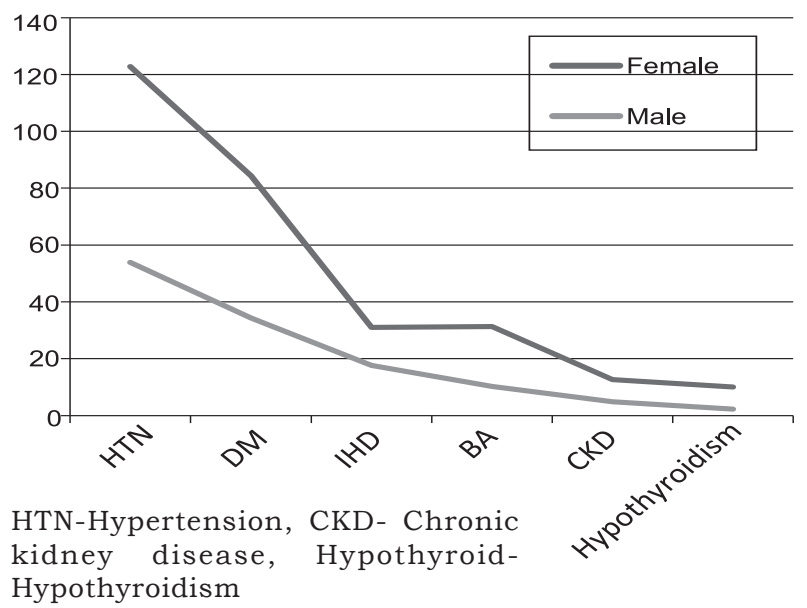

Fig.-2: Comparison of total HBsAg negative Diseased employee $(n=480)$

Table-V

Comparison of patients between those who fail to produce immunity $(N=62)$ and seroprotective group $(n=380)$

\begin{tabular}{lccccc}
\hline $\begin{array}{l}\text { Name of } \\
\text { diseases }\end{array}$ & $\begin{array}{c}\text { Seroprotective } \\
\text { Male } \\
(\mathrm{n}=300)\end{array}$ & $\begin{array}{c}\text { No immunity } \\
\text { Male } \\
(\mathrm{n}=90)\end{array}$ & $\begin{array}{c}\text { Seroprotective } \\
\text { Female } \\
(\mathrm{n}=80)\end{array}$ & $\begin{array}{c}\text { No } \\
\text { immunity } \\
\text { Female } \\
(\mathrm{n}=10)\end{array}$ & $\begin{array}{c}\text { Total } \\
\mathrm{N}=480\end{array}$ \\
\hline HTN & $173(57.67 \%)$ & $38(42.22 \%)$ & $56(70 \%)$ & $8(80 \%)$ & $275(57.29 \%)$ \\
Diabetes & $107(35.66 \%)$ & $25(27.78 \%)$ & $37(46.25 \%)$ & $8(80 \%)$ & $177(36.87 \%)$ \\
Heart disease & $56(18.67 \%)$ & $13(14.44 \%)$ & $11(13.75 \%)$ & $1(10 \%)$ & $81(16.88 \%)$ \\
Bronchial asthma & $30(10 \%)$ & $10(11.11 \%)$ & $18(22.5 \%)$ & $1(10 \%)$ & $59(12.29 \%)$ \\
CKD & $16(5.33 \%)$ & $3(3.33 \%)$ & $7(8.75 \%)$ & 0 & $26(5.41 \%)$ \\
Hypothyroid & $7(2.33 \%)$ & $2(2.22 \%)$ & $7(8.75 \%)$ & 0 & $16(3.33 \%)$ \\
\hline
\end{tabular}




\section{Discussion:}

South East Asia experienced a strong reduction in HBsAg prevalence between 1990 and 2005, particu-larly in the young age groups of 0-14 years that had prevalence levels of $1.2-1.4 \%$ in 2005 . In contrast, South East Asian adult $\mathrm{s}$ appeared to continuously have higher-intermediate $\mathrm{HBsAg}$ prevalence of $5 \%$ to over $6 \%$ in $2005 .{ }^{7}$ Declines in HBV infection prevalence may be related to expanded immunization. ${ }^{7}$ The hepatitis $\mathrm{B}$ vaccine is the mainstay of hepatitis B prevention. From the study it was found that $97.76 \%$ employee are HBsAg negative. Only 2.24\% employee is HBsAg positive and among them $90 \%$ is male. Same findings are seen in different studies. ${ }^{2-7}$ There is a study done in $\mathrm{VNC}^{1}$ in 1997, the study showed that the prevalence of HBsAg among healthy female school age children was $2.3 \%$ by the screening method and $0.8 \%$ by the confirmatory method.

Seroconversion rate of Hepatitis $B$ vaccine globally ranges from $85-90 \%{ }^{15} \mathrm{~A} \mathrm{k}$ Jain et al found seroconversionrate of $98.45 \% .16$ Kruman.S et al found $99 \%$ of subjects developed protective level of Anti-HBs after vaccination with Recombivax HB (Merck) after 1 month of last dose in his study. ${ }^{17}$ Sunita Tripathy et al found $100 \%$ seroconversion in medical students and among them $80 \%$ had high response $(\mathrm{HBsAb}>1000 \mathrm{mIU} / \mathrm{ml})$ after primary vaccination with Engerix $-B$ vaccine. ${ }^{18}$ In this study seroconversion were seen among $432(87.98 \%)$ employee 5 years after 5 th dose of vaccination with Engerix -B vaccine. But we could not evaluate seroconversion rate among the employee after 3rd dose of vaccination with Engerix -B vaccine because there is no such opportunity.

The US Public Health Service Advisory Committee On Immunization Practice (ACPI) recommendation issued in 1987 defined the protective level of anti HBs as greater than or equal to $10 \mathrm{mIU} / \mathrm{ml}$, measured 1-2 months after completion of hepatitis $\mathrm{b}$ vaccine series. ${ }^{19,20} \mathrm{An}$ Indian study conducted by Kunal Das showed that among seroprotected individuals there were 32.4\% hyporesponders (Anti-HBs level 10 $-99 \mathrm{mIU} / \mathrm{ml}$ ) and $52.9 \%$ were responders (anti
HBs $>100 \mathrm{mIU} / \mathrm{ml}) .{ }^{21}$ Sunita Tripathy et al found only $5 \%$ hyporesponder and rest $95 \%$ were responders. ${ }^{18}$ From the study it was found that $58.2 \%$ employee achieved good (responders ) and $18.65 \%$ employee achieved low protective immunity (hyporesponders) against HBV 5 years after vaccination. Brian J Mac Mohan reported males had higher antibody level than females.$^{22}$ Whereas Jane W.S Fang et al found that female children responded with a significantly higher antibody level than male children. ${ }^{23}$ In the study conducted by Mohd. Abdul in Bangladesh found protective level of anti HBs antibody in $85.88 \%$ male and $92.31 \%$ of female. ${ }^{24}$ Glaser et al found in his study that antibody level becomes less in persons undergoing more stress than less stress one. ${ }^{25}$ In this study $344(71.67 \%)$ employee are suffering from hypertension, diabetes , heart disease, chronic kidney disease, bronchial asthma and hypothyroidism. Anti- HBs level is lower among(anti-HB $618 \mathrm{mIU}$ ) them than healthy(anti-HB $875.5 \mathrm{mIU}$ ) employee. Dr Hayley Willecy also found that those above 40 years, obese and smokers are more likely to fail to respond. ${ }^{26}$ In the study conducted by Ann P. Winter, higher proportion of smokers failed to seroconvert after 3 doses of hepatitis vaccine. ${ }^{27}$ In this study, higher antibody level were found among female employee than male.

In this study, no antibody titers or immunity found (<10mIU/mL) among $20.83 \%$ ( 100/480) employee. They were vaccinated previously with 5 dose of Engirex B. Among them 38 male employee are disease free and remaining 62 are diseased. Only $10(11.11 \%)$ out of 90 female employee are failing to show immunity. Incase of male employee, $100(23 \%)$ out of 400 fail to show immunity. The reason of this no response, most probably due to long interval( the study done 13-14 years after vaccination ), male employee, smoking habit and all employee are more than 50 years old ${ }^{1,8,9}$.It has been reported that antibody response decreases with age. R. John Looney found that antibody response was dramatically different between young and elderly group.

Study conducted by Kunal das et al ${ }^{21}$, Seroprotection (Anti-HBs $>10 \mathrm{mIU} / \mathrm{ml}$ ) after 
primary vaccination was achieved in $85.3 \%$ volunteers who were more than 40 years of age. Surg Cdr C N Choudhury et al concluded in his study that higher age at vaccination is a risk factor for low antibody response. ${ }^{28}$ we could not compare elderly group for seroconversion with young because participants of less than 25 years had their primary vaccination 15 years back are not available. There are few long term studies which suggest that hepatitis $B$ vaccine protects an individual for more than 15 years. ${ }^{29}$ Jafar zadeh et al evaluated persistence of antibody level in healthy Iranian children at 10 years after primary vaccination and found that $47.9 \%$ of children had protective level of $\mathrm{HBsAb}>10 \mathrm{~m} \mathrm{IU} / \mathrm{ml} .{ }^{30}$ It has been seen that approximately $20 \%$ geometric mean titer decay occurs per year. ${ }^{31}$ In this study, there is no chance to estimate geometric mean titer decay. We found persistence of antibody level in both sexes and antibody level less among male .In this study mean antibody titer was $610.99 \mathrm{~m}$ $\mathrm{IU} / \mathrm{ml}$ 5years after forth booster dose. Although initially it was thought that Hepatitis B vaccination does not provide indefinite protection. This is no longer considered. Previous reports suggested that primary vaccination would provide protection between 5-7 years. ${ }^{32,} 33$ But subsequently it has been appreciated that protection may be provided for at least 25 years due to long term immunity derived from immunological memory in those individuals who showed adequate response to primary Hepatitis vaccination. ${ }^{34}$.Our study suggested that DNA recombinant vaccine maintains protective level of anti-HBs for more than 10 years. Although, after vaccination the levels of antibody to hepatitis B surface antigen may decline over time, the necessity to maintain anti-HBs concentrations above a certain titer is not widely accepted, since long term immune memory remains intact even in the absence of detectable antibodies. 35 Gabbuti et al suggested that booster dose is not required in immunocompetent individuals. ${ }^{36}$

Duration of vaccine- induced immunity: After three intramuscular doses of hepatitis B vaccine, more than $90 \%$ of healthy adults and more than $95 \%$ of infants, children, and adolescents (from birth to 19 years of age) develop adequate antibody responses. However, there is an age-specific decline in immunogenicity. 8,37,38 But immune memory remains intact for more than 20 years following immunization, and both adults and children with declining antibody levels are still protected against significant HBV infection (i.e., clinical disease, HBsAg antigenemia, or significant elevation of liver enzymes). $6,8,39,40$ In this study good immunity $(>100 \mathrm{mIU} / \mathrm{mL})$ found among $58.2 \%$ employee.

Vaccine Failure: A small percentage of adults fail to mount an immunological response despite completion of the immunization schedule. Several factors have been associated with nonresponse to hepatitis B vaccine. These include vaccine factors (e.g., dose, schedule, injection site) and host factors are older age (40 years and older), male sex, obesity, smoking, and chronic illness have been independently associated with nonresponse to hepatitis B vaccine. $8,18,41,42$ Preterm babies $<2 \mathrm{Kgs}$ are also known to show insufficient responses. ${ }^{41}$

Cost-effectiveness: Cost is an important issue for a resource poor country like Bangladesh. Cost analysis done in countries with low endemicity shows that routine vaccination against HBV costs about $\$ 6.9 \times 3=\$ 207$ $(542 * 3=1626 /$ taka $)$ per life saved, compared with over \$228-3184.71(17972- 250000 taka) yearly for HBsAg positive chronic hepatitis or HCC per patient. ${ }^{43}$ In 2014-15,\$13516 (1182652/taka)were spent for the management $17 \mathrm{HBsAg}$ positive patient. On the other hand, to reduce the risk of ischemic heart disease, myocardial infarction and brain stroke \$86817.32 (6815159.99/taka)were consumed (as cost of lipid lowering drugs) and it will be continued life long. ${ }^{43}$ Economic analysis of vaccinating Asian Americans in Philadelphia was found to be cost-effective and even costbeneficial with a benefit-cost ratio of $4.4: 1^{44}$ However Bangladesh is a medium income country(per capita income is $\$ 1314)$, literacy rate is $60 \%$, safe drinking water is $95 \%$, purchase capacity increased more than previous, vaccine is available and price is affordable and community clinic is available everywhere. All children are vaccinated against HBV since 2004 by EPI schedule. So all adult 
person can be vaccinated with 3 dose schdule to protect future generation. There is no need of screening test and measurement of antibody titer for general public .8, 45

HBV infection is uncommon among adults in the general population (the lifetime risk of infection is less than $20 \%)^{8}$, it is highly prevalent in certain groups. Risk for infection varies with occupation, lifestyle, or environment. Generally, the highest risk for HBV infection is associated with lifestyles, occupations, or environments in which contact with blood from infected persons is frequent. Pregnancy is a risky condition for women and regular shaving, field work is a risky condition for men. It has been found that about 1.2-3.5\% of the pregnant ladies in Bangladesh are $\mathrm{HbsAg}$ positives and that $22-38 \%$ of them is also $\mathrm{HBeAg}$ positives. ${ }^{3}$ The risk of perinatal transmission is about $10 \%$ if the mother is positive only for HBsAg. Pregnancy is not a contraindication to vaccination. $^{8}$ As many as $90 \%$ of infant $\mathrm{HBV}$ infections will progress to chronic infection. ${ }^{8}$ Delaying vaccination for the first six weeks will put $70-90 \%$ babies at risk of acquiring perinatal infection. ${ }^{3}$ If couple is vaccinated one by one, it will be economic for the family and beneficial both for society and country.

\section{Conclusion:}

The vaccine is $80 \%$ to $100 \%$ effective in preventing infection or clinical hepatitis in those who receive the complete vaccine series. For adults and children with normal immune status, booster doses of vaccine are not recommended. Serologic testing is not recommended before routine vaccination of infants, children, or adolescents. Routine serologic testing to assess immune status of vaccinees is not recommended.

These data helps to justify economic analysis of HBV vaccination in Bangladesh. To analyze cost benefit/cost effectiveness, present study is a guide for Bangladesh, as its infrastructure of health care and disease prevalence are improving than previous. Bangladesh needs an effective vaccination strategy against HBV. So it is presumptive that vaccine is safe and effective and we can continue vaccination without prior screening test. Healthy life style and good behavior increase immune protection.
Limitation:We cannot compare Anti-HBs level with body weight and smoking.

\section{Acknowledgements}

We are grateful to Dr.Mohammad Farasuddin and Dr. Atiur Rahman, Ex-Governor and present Governor of Bangladesh Bank, respectively for providing valuable vaccination and 50yrs health check up program.

Competing interests: I declare that I have no conflict of interest.

\section{References:}

1. Laskar MS, Harada N, Khan F. Prevalence of Hepatitis B Surface Antigen (HBsAg) in Viqarunnesa Noon Girl's School Children in Dhaka, Bangladesh. Cent Eur J PublicHealth 1997; 5: 202-4.

2. Zaki $\mathrm{H}^{1}$, Darmstadt GL, Baten A, Ahsan CR, Saha SK.Seroepidemiology of hepatitis B and delta virus infections in Bangladesh. J Trop Pediatr. 2003 Dec;49(6):371-4.

3. Rumi MAK, Begum K, Hassan M, et al. Detection of Hepatitis B Surface Antigen in Pregnant women attending a public Hospital for Delivery: Implication for Vaccination Strategy in Bangladesh. Am J Trop Med Hyg 1998; 59: 318322.

4. de Francisco A, Hall AJ, Alam N, Hawkes S, Azim T. Hepatitis B Infection in Bangladeshi Mothers and Infants. Southeast Asian J Trop Med Public Health 1999; 30: 296-8.

5. Mahtab MA ${ }^{1}$, Rahman S, Karim MF, Khan M, Foster G, Solaiman S, Afroz S;Epidemiology of hepatitis $B$ virus in Bangladeshi general population. Hepatobiliary Pancreat Dis Int. 2008 Dec;7(6):595600.

6. World Health Organization. Hepatitis B. Available from [Link]

7. J.J.Ott,G.A.Stevens, j.Groeger,s.T. Wiersma; Global Epidemiology of hepatitis b virus infection: new estimates of age-specific $\mathrm{HBsAg}$ seroprevalence and endemicity; Vaccine 30(2012) 2212-2219.

8. Hepatitis B; Epidemiology and Prevention of Vaccine-Preventable Diseases: Centers for Disease Control and Prevention 1600 Clifton Rd Atlanta, GA 30333

9. Recommendation of the Immunization Practices Advisory Committee (ACIP) Inactivated Hepatitis B Virus Vaccine; June 25, 1982 / 31(24);31722,327-8.

10. Viral Hepatitis Prevention Board. Prevention and control of hepatitis $B$ in the community. Communicable Disease Series, 1996, 1. 
11. Vijayakumar V, Hari R, Parthiban R, Mehta J, Thyagarajan S P. Evaluation of immunogenicity and safety of Genevac B: A new recombinant hepatitis $b$ vaccine in comparison with Engerix $\mathrm{B}$ and Shanvac B in healthy adults. Indian $\mathrm{J}$ Med Microbiol 2004;22:34-8

12. Dienstag JL, Stevens CE, Bhan AK, et al. Hepatitis $B$ vaccine administered to chronic carriers of hepatitis B surface antigen. Ann Intern Med 1982; 96:575-9.

13. World Health Organization; immunization coverage; fact sheet N378; updated September 2015.

14. Elisabetta Franco, Barbara Bagnato, Maria Giulia Marino, Cristina Meleleo, Laura Serino, and Laura Zaratti ; Hepatitis B: Epidemiology and prevention in developing countries; World J Hepatol. 2012 Mar 27; 4(3): 74-80.

15. Mohammad Zeeshan et al.Evaluation of immune response to hepatitis $\mathrm{B}$ vaccine in healthcare workers at a tertiary care hospital in Pakistan. BMC Infectious diseases 2007, 7:120.

16. Ajay Kumar Jain et al. Hepatitis $b$ vaccine in the EPI schedule .Indian J Pediatr .2005; 72(8):66164. (cross reference)

17. Krumanet al. Recombivax HB. Data on file at Merck Research laboratory(cross reference)

18. Sunita Tripathy, HC Sati, Puspa, Seema Saha, Ravi Shankar, VK Singh; Study Of Immune Response After Hepatitis B Vaccination In Medical Students And Health Care Workers: Indian J. Prev. Soc. Med. Vol. 42 No3,2011.

19. Hepatitis B virus vaccine (PF) IM.www. Med Scape. com.2009.

20. Zajae BA,West DJ et al.Overview of clinical studies with Hepatitis b.

21. Kunal Das, RK Gupta et al. Immunogenicity and reactogenicity of a recombinant Hepatitis B vaccine in subjects over 40 years of age and response to a booster among non responders. World $\mathrm{J}$ of gastroenterology 2003 may; 9(5):1132-34.

22. Brian J McMahan et al. Antibody level and protection after Hepatitis B Vaccination. Result of a 15 year follows up. www.annals.org/cgi 2007.

23. J Ane W.S Fang et al. Female children respond to Recombinant Hepatitis b Vaccine with higher titer than male.Journal of Tropical Pediatrics 1994,40(20;104-107.

24. Md Abdul Ahad et al.Role of booster dose on antibody titre after Recombinant hepatitis b vaccine. Journal of Medicine .2009, 10(2):67-76.
25. Glaser R. et al. Stress induced modulation of immune response to recombinant hepatitis-B vaccine. Psychosome Med 1992; 54:22-29.

26. H.Willacy ET al.Hepatitis $B$ vaccination and prevention (Doctors/patients) U K.16 Oct 2009, www.patient co.uk>patient plus.

27. Ann P.Winter,Edward AC."Influence of smoking on immunological response to hepatitis b vaccine." Vaccine 1994,12(9):771-772.

28. Surg Cdr C N Choudhuryet at al.Antibody to Hepatitis B surface antigen in vaccinated health care workers.MJAFI 2008;64:329-332

29. Banatvala JE and Van Damme P.HepatitisB vaccine-do we need boosters?. Journal of Viral Hepatitis 2003; 10(1):1-6.

30. A. Jafar Zadeh et al. "Persistence of anti HBS antibody and immunological memory in children vaccinated with Hepatitis B vaccine at birth.2006. $\mathrm{J}$ Ayub medical college Abbottabaf; 18(4).

31. Ching Wen Wang,Li-Chieh Wang et al."Long time follow up of hepatitis b surface antibody level in subjects receiving universal hepatitis $\mathrm{b}$ vaccination in infancy in an area of hyperendemicity. Clin Diag Lab Immunology 2005: Dec, 12(12):1442-47.

32. Krugman, Davidson."Hepatitis B vaccine".Yale J of Biology \& medicine, 1987.

33. Peterson,K M."Duration of hepatitis b immunity in low risk childrenreceiving Hepatitis B vaccine from birth". The Pediatric Infectious Disease Journal 23:650, 2004. (cross reference)

34. Vandamme PVan Herck K."A review of the long term protection after hepa titis $b$ vaccine. Travel Medicine and Infectious Diseases; 5 (2): 79-84, 2007. (cross reference)

35. Poovorawan Y, Theambonlers A, Hirsch P, et al. Persistence of antibodies to the surface antigen of the hepatitis B virus (anti-HBs) in children subjected to the Expanded Programme on Immunization (EPI), including hepatitis-B vaccine, in Thailand. Ann Trop Med Parasitol 2000; 94: 615-21. (cross reference)

36. Gabbuti,A et al . "Long term immunogenicity of Hepatitis B vaccination in a cohort of Italian healthy adolescents.Vaccine25 (16); 3129-3132, 2007. (cross reference)

37. Krugman S, Holley HP Jr, Davidson M, et al. Immunogenic effect of inactivated hepatitis B vaccine: comparison of $20 \mathrm{ug}$ and $40 \mathrm{ug}$ doses. $\mathrm{J}$ Med Virol 1981; 8:119-21. (cross reference)

38. Szmuness W, Stevens CE, Harley EJ, et al. The immune response of healthy adults to a reduced dose of hepatitis B vaccine. J Med Virol 1981; 8:123-9. 
39. Duval B, Gilca V, Boulianne N, de Wals P, Masse R, Trudeau G. Response to hepatitis B booster in a large cohort of previously vaccinated adolescents. Presented at the Seventh Annual Conference on Vaccine Research of the National Foudation for Infectious Diseases, 24-26 May 2004 at Airlington,Virginia

40. Poovarawan Y,Theamboonlers A, Vimolket T, et al. Impact of Hepatitis B immunisation as part of the EPI. Vaccine 2000; 19: 943-9 .

41. Margolis H, Moyer L. Ask the experts: Needle Tips. Fall/Winter 1999-2000. Available from: www.immunize.org [accessed December 4, 2005].
42. Middleman AB, Kozintez CA, Robertson LM, DuRant RH, Emans SJ. Effect of Late Doses on the achievement of Seroprotection and Antibody Titer Levels with Hepatitis B Immunization among Adolescents. Pediatrics 2001; 107: 1065-1069.

43. Records from Medical center of Bangladesh Bank.

44. Deuson RR, Brodovicz KG, Barker L, Zhou F, Euler GL. Economic Analysis of a Child Vaccination project among Asian Americans in Philadelphia, Pa. Arch Ped Adol Med 2001; 155: 909-14(cross reference)

45. HSIP FAQ Health Sciences Immunization Program, 2009-2015 University of Washington.https:// depts.washington.edu/chsweb/faq/hsip-faq. 